\title{
The influence of sulfathiazole on the macroalgae Ulva lactuca
}

\author{
Sara Leston ${ }^{\mathrm{a}, \mathrm{b}, *}$, Margarida Nunes ${ }^{\mathrm{a}, \mathrm{b}}$, Ivan Viegas ${ }^{\mathrm{a}, \mathrm{c}}$, Carolina Nebot $^{\mathrm{d}}$, Alberto Cepeda ${ }^{\mathrm{d}}$, \\ Miguel Ângelo Pardal ${ }^{\mathrm{a}}$, Fernando Ramos ${ }^{\mathrm{b}}$ \\ ${ }^{a}$ CFE - Centre for Functional Ecology, Department of Life Sciences, University of Coimbra, Apartado 3046, 3001-401 Coimbra, Portugal \\ ${ }^{\mathrm{b}}$ CEF - Center for Pharmaceutical Studies, Health Sciences Campus, Pharmacy Faculty, University of Coimbra, Azinhaga de Santa Comba, $3000-548$ Coimbra, Portugal \\ ${ }^{c}$ CNC - Centre for Neurosciences and Cell Biology, Department of Life Sciences, University of Coimbra, 3001-401 Coimbra, Portugal \\ ${ }^{\mathrm{d}}$ Departamento de Nutrición y Bromatología, Facultad de Veterinaria, Universidad de Santiago de Compostela, Lugo 27002, Spain
}

\section{H I G H L I G H T S}

- Sulfathiazole shows high stability in seawater with $18 \%$ degradation over $5 \mathrm{~d}$.

- Ulva lactuca reduced the concentrations of STZ in the water by efficiently taking up the drug.

- U. lactuca kept the internal values constant most likely through a detoxification mechanism.

- Sulfathiazole slightly inhibited the growth of U. lactuca after $96 \mathrm{~h}$ of exposure.

- Macroalgae should be considered as potential bioindicator species in risk assessment of STZ.

\section{A R T I C L E I N F O}

\section{Article history:}

Received 7 August 2013

Received in revised form 9 December 2013

Accepted 11 December 2013

Available online 3 January 2014

\section{Keywords:}

Antibiotic

Sulfathiazole

Macroalgae

Ulva lactuca

Bioindicators

Contamination

\begin{abstract}
A B S T R A C T
Sulfonamides (SA) are a class of antibiotics routinely found in environmental matrices and therefore their role as contaminants should be investigated in non-target organisms. With this purpose the present experimental work has evaluated the exposure of the chlorophycean Ulva lactuca L. to sulfathiazole (STZ), a SA drug commonly used in aquaculture, at two concentrations representing prophylactic $\left(25 \mu \mathrm{g} \mathrm{mL}^{-1}\right)$ and therapeutic $\left(50 \mu \mathrm{g} \mathrm{mL}^{-1}\right)$ administrations. Results showed that STZ exhibits high stability in seawater with only $18 \%$ degradation over the $5 \mathrm{~d}$ assay at both dosages tested. Also, macroalgae demonstrated an efficient uptake capacity with constant internal concentrations after $24 \mathrm{~h}$ regardless of the external solutions and thus should be considered as a bioindicator species in risk assessment. Both STZ concentrations induced a slight inhibition of the macroalgae growth after $96 \mathrm{~h}$.
\end{abstract}

(c) 2013 Elsevier Ltd. All rights reserved.

\section{Introduction}

Natural ecosystems are continuously challenged by change whether gradually and at smaller dimensions or at a massive and abrupt pace, shifting the systems away from optimum conditions. Chemical contamination of anthropogenic origin represents a significant stressor to the environment since it can be responsible for adverse ecological effects in the systems (Swindol et al., 2000). Environmental contaminants comprise various classes of substances with different chemical properties from metals to organic compounds. Within this category, pharmaceuticals represent a particular group of substances to which special attention

* Corresponding author at: CFE - Centre for Functional Ecology, Department of Life Sciences, University of Coimbra, Apartado 3046, 3001-401 Coimbra, Portugal. Tel.: +351 239855760x348; fax: +351239855789.

E-mail address: saraleston@ci.uc.pt (S. Leston). must be given since they are designed to cross biological barriers and induce specific responses (Halling-Sorensen et al., 1998). The potential harm resulting from their administration in human and veterinary medicine is well reflected in current legislations, which set maximum levels of veterinary drug residues in food products to assure human health protection (EC Regulation 37/2010). Limits in environmental matrices, however, are more difficult to establish due to the very high number of drugs available and the uncertainty of responses in non-target organisms. Due to the impossibility of studying the whole ecosystem to determine the effects of a given drug, several species have become increasingly used as bioindicators and biomonitors of ecological distress (Villares et al., 2002; Melville and Pulkownik, 2007). In this sense a bioindicator will indicate exposure to a given contaminant by its presence or absence whereas a biomonitor must be able to accumulate the compound in its tissues and provide a detectable and time-integrated estimate of the available concentration (Rainbow and 
Phillips, 1993; Melville and Pulkownik, 2007). When considering a particular group of organisms for both functions attention to their characteristics is very important and should include wide geographic distribution, sedentarity and unequivocal identification (Rainbow and Phillips, 1993; Melville and Pulkownik, 2007). Usually, animal species are selected but primary producers are also being researched for these roles, including macroalgae (Coogan et al., 2007; Melville and Pulkownik, 2007; Akcali and Kucuksezgin, 2011; Costa et al., 2011; Leston et al., 2011). Macroalgae contribute to aquatic ecosystems with high biomass production and also represent an important link in the trophic webs, which can lead to the biomagnification of contaminants. Among the species already investigated for this role is the estuarine chlorophycean Ulva lactuca L., which meets the requirements described above. It also has high surface area to volume ratio that translates in high growth rates and tolerates fluctuating salinities and temperature commonly found in transient environments.

Sulfonamides (SA) are extensively used pharmaceuticals with antibacterial activity against a large range of infectious agents by competitively inhibiting the use of $p$-aminobenzoate in the biosynthesis of folic acid (Braschi et al., 2010; Michelini et al., 2012). Sulfonamides are commonly administered in the treatment of respiratory and urinary infections and in animal husbandries are used for prophylactic and therapeutic purposes (Boreen et al., 2004; Sarmah et al., 2006). Sulfathiazole (STZ) is a routinely prescribed drug that, together with other SA, has repeatedly been detected in the environment, reaching the water bodies discharged in wastewaters from hospitals, sewage treatment plants and even aquaculture facilities. The available studies on STZ's ecotoxicity to non-target organisms (e.g. bacteria, microalgae, plants, invertebrates and fish) include acute and chronic effects demonstrated in inhibition of growth (Brain et al., 2004; Baran et al., 2006; Kim et al., 2009; Ji et al., 2012). Due to SA's amphoteric nature the extent to which the current filtering systems and depuration actions can prevent their release to the environment is strongly related with their sorption capacity, which in turn is dependent on soil/ sediment composition and $\mathrm{pH}$ (Halling-Sorensen et al., 1998; Kahle and Stamm, 2007; García-Galán et al., 2008; Lertpaitoonpan et al., 2009; Braschi et al., 2010; Hruska and Franek, 2012).

The ecological consequences of the presence of STZ in the environment and the possible effects induced in non-target organisms which may include changes in growth rate, reproduction and even lethal toxicity, require further research (Halling-Sorensen et al., 1998; Brain et al., 2004, 2008; Kümmerer, 2009; Leston et al., 2011; Ji et al., 2012). To enhance the knowledge on these effects the present study describes experimental data on the exposure of the green macroalgae $U$. lactuca L. to STZ focusing on the following points: (i) to investigate the stability of STZ in natural seawater, (ii) to assess the influence of STZ on U. lactuca's growth at two concentrations simulating prophylactic and therapeutic dosages (iii) to investigate the possibility of bioaccumulation and biomagnification of the contaminant through the trophic web and (iv) to evaluate the potential use of $U$. lactuca as a bioindicator and biomonitor for the presence of STZ.

\section{Experimental}

\subsection{Chemicals and solutions}

The STZ analytical standard (Fig. 1) and the internal standard sulfadimethoxine-d6 were purchased from Sigma-Aldrich (Steinheim, Germany). Formic acid and ethyl acetate were acquired from Merck (Darmstadt, Germany) while methanol and acetonitrile were purchased from Scharlau Chemie (Barcelona, Spain). All chemicals were filtered and degassed and of liquid chromatogra-

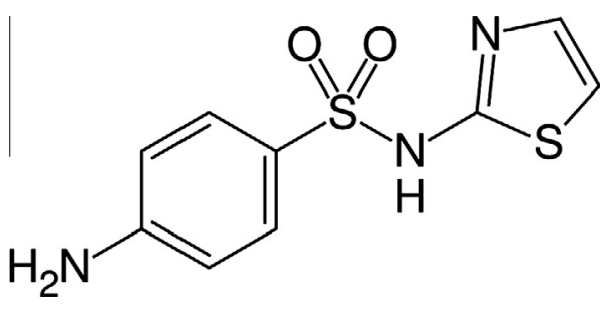

Fig. 1. Chemical structure of sulfathiazole.

phy (LC) analytical grade. Ultrapure water was obtained daily from a Milli-Q water purification system (Millipore, Bedford, MA, USA).

The internal standard solution was prepared through the dilution of sulfadimethoxine-d6 in methanol $\left(0.6 \mathrm{mg} \mathrm{mL}^{-1}\right)$. An individual STZ standard stock solution of $1 \mathrm{mg} \mathrm{mL}^{-1}$ was prepared by dissolving $50 \mathrm{mg}$ of the compound in $50 \mathrm{~mL}$ of methanol and kept at $-20^{\circ} \mathrm{C}$ in an amber glass bottle. Just before beginning the experiment two intermediate standard solutions were adjusted from the stock by dilution in filtered natural seawater to obtain two final concentrations of $25 \mu \mathrm{g} \mathrm{mL}^{-1}$ and $50 \mu \mathrm{g} \mathrm{mL}^{-1}$. Both solutions intend to simulate discharges from aquaculture tanks after the administration of bath treatments with concentrations representing hypothetical dosages for prophylaxis $\left(25 \mu \mathrm{g} \mathrm{mL}^{-1}\right)$ and therapy $\left(50 \mu \mathrm{g} \mathrm{mL}^{-1}\right)$. In order to facilitate the comparison, these concentrations are based on previous experimental designs with furaltadone and chloramphenicol where the same values were tested (for further details see Leston et al., 2011, 2013) and were based on information given by veterinarians.

\subsection{Sampling and acclimation}

U. lactuca fronds were collected at the Mondego Estuary (Portugal, $40^{\circ} 80^{\prime} \mathrm{N}, 8^{\circ} 50^{\prime} \mathrm{W}$ ) during low tide. Macroalgae were thoroughly washed and rinsed to assure the absence of organisms and debris and then placed in refrigerated coolers for transportation to the laboratory. Fresh natural seawater was also collected at the site in acid washed amber bottles and upon arrival, immediately filtered $(0.45 \mu \mathrm{m})$ and stored at $4{ }^{\circ} \mathrm{C}$ until use.

To simulate the optimum conditions for U. lactuca the experiment was conducted in a controlled room with the photoperiod set to $14: 10 \mathrm{LD}$ (light:dark), $25^{\circ} \mathrm{C}$ and under $80 \mu \mathrm{mol}$ photons $\mathrm{m}^{-2} \mathrm{~s}^{-1}$ of white fluorescent light. Tanks with $40 \mathrm{~L}$ capacity were filled with filtered seawater ( $35 \mathrm{psu}$ ) to which was added Provasoli Enriched Medium to a final concentration of $20 \mu \mathrm{L} \mathrm{mL}^{-1}$ (PES; Provasoli, 1963 and modified by Bold and Wynne (1978)) and aerated for $48 \mathrm{~h}$. After this time fronds were once more carefully inspected before placement in the tanks. Acclimation was kept for three weeks prior to the beginning of the experiment.

\subsection{Experimental design}

In the preceding $24 \mathrm{~h}$ acid washed Erlemeyer flasks were filled with $250 \mathrm{~mL}$ of seawater and $5 \mathrm{~mL}$ of PES, placed on orbital shakers and acclimated during that period in the same conditions described above but with aeration replaced by a constant horizontal stir at $100 \mathrm{rpm}$. Right before start algal disks with $\emptyset 5 \mathrm{~cm}$ (approx. $20 \mathrm{~cm}^{2}$ ) were cut, separated in the different groups, weighed and photographed. Sulfathiazole solutions were prepared and added to the corresponding flasks. Based on the concentrations, two groups, designated $\mathrm{P}$ and $\mathrm{T}$, were established with group $\mathrm{P}$ testing the prophylactic concentration $\left(25 \mu \mathrm{g} \mathrm{mL}^{-1}\right)$ and group $\mathrm{T}$ testing the therapeutic dosage $\left(50 \mu \mathrm{g} \mathrm{mL}^{-1}\right)$. Each group was composed of three replicates per sampling time (one flask constituted one replicate), with each replicate containing three algal disks. Two 
control groups were also set under the same conditions. Control A was established to verify the behavior of STZ in seawater for both concentrations $\mathrm{P}$ and $\mathrm{T}$ without the presence of macroalgae whereas Control B was prepared to assess the natural growth of $U$. lactuca in the absence of the antibiotic. The effect of methanol present in the solutions (the same volume was used) was assessed in a previous work following the same experimental design and for that reason was not replicated here (for further reading see Leston et al., 2011). To prevent losses due to evaporation but still allowing gas exchange every flask was covered with glass lids. Water samples and photographs to register growth variations were taken at the following times: $0,1,2,5,8,12,16,24,48,72,96$ and $120 \mathrm{~h}$.

\subsection{Sulfathiazole quantification}

\subsubsection{Water analysis}

At each sampling time, temperature, salinity and $\mathrm{pH}$ were measured and water samples filtered through glass fiber filters ( $\varnothing$ $0.22 \mathrm{~mm}$ ) and immediately frozen at $-20^{\circ} \mathrm{C}$ until extraction.

Internal standard ( $15 \mu \mathrm{L}$ of IS working solution at $\left.1 \mu \mathrm{g} \mathrm{mL}^{-1}\right)$ was added to the water samples for STZ quantification which were then transferred to appropriate LC-UV vials and placed in a Gilson modular system (Gilson, Middleton, WI, USA) equipped with a pump (Gilson 321) and an automatic injector (Gilson 234) coupled to a UV/Vis detector (Gilson 155). The chromatographic column used for separation was a 250-4 LiChrospher 100 RP-18 column (Merck, Darmstadt, Germany) and a NewGuard C18 pre-column (PerkinElmer, Norwalk, USA) equilibrated at $25^{\circ} \mathrm{C}$. Elution of STZ was conducted in isocratic mode with a mobile phase constituted by: A) $0.1 \%$ formic acid in ultrapure water ( $70 \%$ ) and B) methanol (30\%). $20 \mu \mathrm{L}$ of sample were injected, flowing at a rate of $1.2 \mathrm{~mL} \mathrm{~min}^{-1}$ for a total run time of $10 \mathrm{~min}$.

\subsubsection{Macroalgae}

To establish the uptake and accumulation capacity of $U$. lactuca of STZ in the water, internal concentrations were quantified with a LC-MS/MS methodology. After removal from the water, algal disks were paper-dried to remove the excess water, weighed and frozen at $-20^{\circ} \mathrm{C}$. For extraction of STZ in U. lactuca, $100 \mathrm{mg}$ of sample were thoroughly weighed, minced and placed in $2 \mathrm{~mL}$ Eppendorf tubes followed by addition of $1.5 \mathrm{~mL}$ of acetonitrile and $15 \mu \mathrm{L}$ of IS working solution $\left(1 \mu \mathrm{g} \mathrm{mL} \mathrm{m}^{-1}\right)$. After vortex mixing for $1 \mathrm{~min}$ and sonication for $10 \mathrm{~min}$, samples were centrifuged for $10 \mathrm{~min}$ at $1509 \mathrm{~g}$ and the supernatant collected to a clean $10 \mathrm{~mL}$ conical centrifuge glass tube. The procedure was repeated with another $1.5 \mathrm{~mL}$ of acetonitrile added to the remnant sample. The supernatant resulting from the second extraction was then combined with the previous and the mixture evaporated to dryness under gentle nitrogen stream at $40^{\circ} \mathrm{C}$. The dry residue was reconstituted with $0.2 \mathrm{~mL}$ of $0.1 \%$ of formic acid in acetonitrile and placed in an amber glass vial. Chromatographic analysis was carried out with Gemini $3 \mu \mathrm{C} 18110 \mathrm{~A}(50 \mathrm{~mm} \times 4.60 \mathrm{~mm})$ analytical column in conjunction with a Security Guard Cartridge Gemini C18 $(4 \times 3.0 \mathrm{~mm})$, both from Phenomenex (Macclesfield, UK). Elution was run in gradient mode with a mobile phase consisting of $0.1 \%$ formic acid in water (solvent $\mathrm{A}$ ) and $0.1 \%$ formic acid in methanol (solvent B), pumped at $500 \mu \mathrm{L} \mathrm{min}{ }^{-1}$. The following gradient was used: $0-1 \mathrm{~min}, 95 \%$ A; 1-8 min, 0\% A; 8-10 min, 95\% A; 10-15 min, 95\% A.

\subsection{Growth}

The influence of STZ on U. lactuca's growth was assessed by analysis of the variations in disk area. Photographs of each individual disk were taken at the beginning and end of each sampling time and analyzed with a computer-assisted software (Adobe ${ }^{\circledR}$ Photoshop ${ }^{\circledR}$ CS5 extended).

\subsection{Statistics}

After testing data for normality and homoscedasticity a oneway analysis of variance (ANOVA) was used to compare the differences in STZ uptake at both concentrations and to assess its influence in growth. The level of statistical significance for all analyses was inferred at $p<0.05$. ANOVA was run with GraphPad Prism $^{\circledR} 5$ software (Graph Pad Software, Inc.).

\section{Results and discussion}

\subsection{Degradation of STZ in water}

Solutions of STZ in seawater for groups P and T were prepared and analyzed previously to assure the proposed concentrations were obtained (Fig. 2). Control A samples taken at time 0 confirmed both concentrations, respectively $24.81 \pm 0.1$ and $48.96 \pm 0.7 \mu \mathrm{g} \mathrm{mL}{ }^{-1}$. During the first $24 \mathrm{~h}$, the prophylactic control group presented a $19 \%$ decrease in concentration whereas in the same time frame the therapeutic group exhibited only an $8 \%$ reduction. In the following days the decline in concentrations decelerated and at the end of the trial the values of STZ recovered corresponded to $72 \%$ of the initial amount applied for both dosages tested.

The degradation of pharmaceuticals in surface waters occurs mainly through two important abiotic processes, hydrolysis and photolysis (Andreozzi et al., 2003; Park and Choi, 2008). However, many compounds including SA drugs are designed to resist hydrolysis after oral administration to maintain their biological activity thus relying on photolysis as the main degradation mechanism (Andreozzi et al., 2003; Boreen et al., 2004; Kümmerer, 2009). However, studies have reported that SA drugs are sensitive to light but not readily photodegradable (Lunestad et al., 1995; Kümmerer, $2009)$ and generally presenting long half-life times $\left(t_{1 / 2}\right)$ (Andreozzi et al., 2003; Boreen et al., 2004). Other studies on SA photodegradation have described that there is dependence on $\mathrm{pH}$ and in the specific case of STZ, values above 7 would accelerate the degradation rate, which would result in lower $t_{1 / 2}$. Researchers have
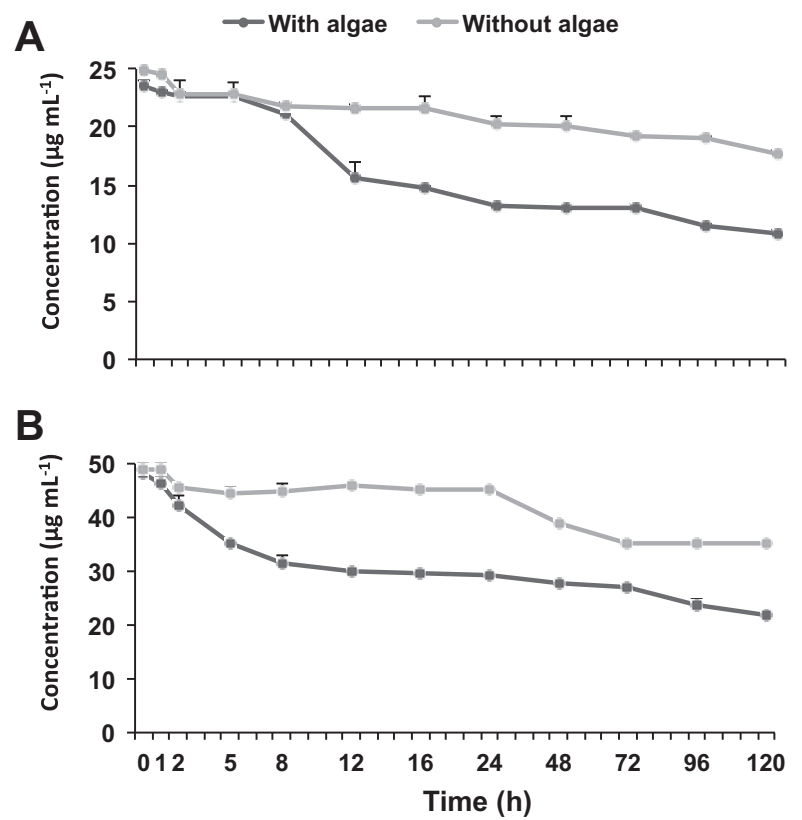

Fig. 2. (A) Stability test of STZ in aqueous solution with and without $U$. lactuca at $25 \mu \mathrm{g} \mathrm{mL} \mathrm{m}^{-1}$. (B) Stability test of STZ in aqueous solution with and without $U$. lactuca at $50 \mu \mathrm{g} \mathrm{mL}^{-1}$. Data represent mean values of three independent replicates. 
also found that the concentration of SA would also be negatively influenced by the presence of natural catalysts occurring in environmental waters such as nitrate $\left(\mathrm{NO}_{3}^{-}\right)$(Andreozzi et al., 2003). Thus, when comparing the results obtained in the present work with these studies, at the simulated temperature $\left(25^{\circ} \mathrm{C}\right)$, with a $\mathrm{pH}$ of 7 and the presence of $\mathrm{NO}_{3}^{-}$(supplied to the medium together with other nutrients to ensure optimum growth conditions) STZ should have presented a lower $t_{1 / 2}$, which was not verified.

Therefore, under the present experimental conditions the high stability of STZ in seawater is in agreement with other researches that state SA drugs are resistant to degradation and can persist for long time periods in the environment (Halling-Sørensen et al., 1998; Kümmerer, 2001, 2009; Baran et al., 2006; García-Galán et al., 2008).

\subsection{STZ uptake}

To evaluate the potential role of $U$. lactuca as a bioindicator and/ or biomonitor for the presence of STZ in the aquatic environment it was essential to assess its capacity for uptake at both dosages tested. Each macroalgal disk was analyzed to determine the internal concentration present and to establish a comparison between these values and the remainder concentrations in the surrounding water. The pattern of uptake was similar for both groups [P] and [T] with the highest amounts reached at time 0 , respectively $6.81 \pm 0.35$ and $7.32 \pm 0.15 \mu \mathrm{g} \mathrm{g}^{-1}$ (Figs. $3 \mathrm{~A}$ and $4 \mathrm{~A}$ ). From the initial values, concentrations presented a slight decrease in the following $24 \mathrm{~h}$ and again at $48 \mathrm{~h}$ remaining constant thereafter, with minimum values of $5.21 \pm 0.15$ and $4.78 \pm 0.16 \mu \mathrm{g} \mathrm{g}^{-1}$ for $\mathrm{P}$ and $\mathrm{T}$ respectively. No statistical differences were found between both groups at $p>0.05$. Considering the concentrations of STZ in the water, the pattern was very different from control A, for both groups. After $24 \mathrm{~h}$, group P presented a reduction of $44 \%$ of the initial concentration $\left(13.23 \pm 0.15 \mu \mathrm{g} \mathrm{g}^{-1}\right)$ whereas concentrations in group $\mathrm{T}$ decreased to $40 \%$ of the initial value $\left(29.18 \pm 0.61 \mu \mathrm{g} \mathrm{g}^{-1}\right)$ during the same time (Fig. 2). At the end of the experiment STZ present in the water was less than $46 \%$ in both groups, a much lower percentage compared to the control groups where $72 \%$ of the starting values were still detected which may be attributed to uptake from the macrophytic biomass.

One important descriptor in drug development is the octanolwater partition coefficient $\left(K_{\text {ow }}\right)$ that provides a good estimate of the hydrophilicity of a given substance and thus is used to predict membrane permeability. The same coefficient is applied in environmental risk assessment to anticipate the uptake efficiency of contaminants by non-target organisms and their subsequent bioaccumulation potential (Walker et al., 2006; Fatta-Kassinos et al., 2011). With a $\log K_{\text {ow }}$ of 0.05 (Pérez et al., 2005) STZ is a highly hydrophilic compound that can easily penetrate cell membranes through simple passive diffusion. However, despite the high levels of STZ available in the water the internal concentrations remained low and constant when compared to the external values. In a previous work to test the effects of furaltadone under the same experimental conditions, U. lactuca was able to take up almost $19 \mu \mathrm{g} \mathrm{g}^{-1}$ within the first hours of exposure to the same prophylactic dosage (Leston et al., 2011). This nitrofuran antibiotic presents a $\log K_{\text {ow }}$ of
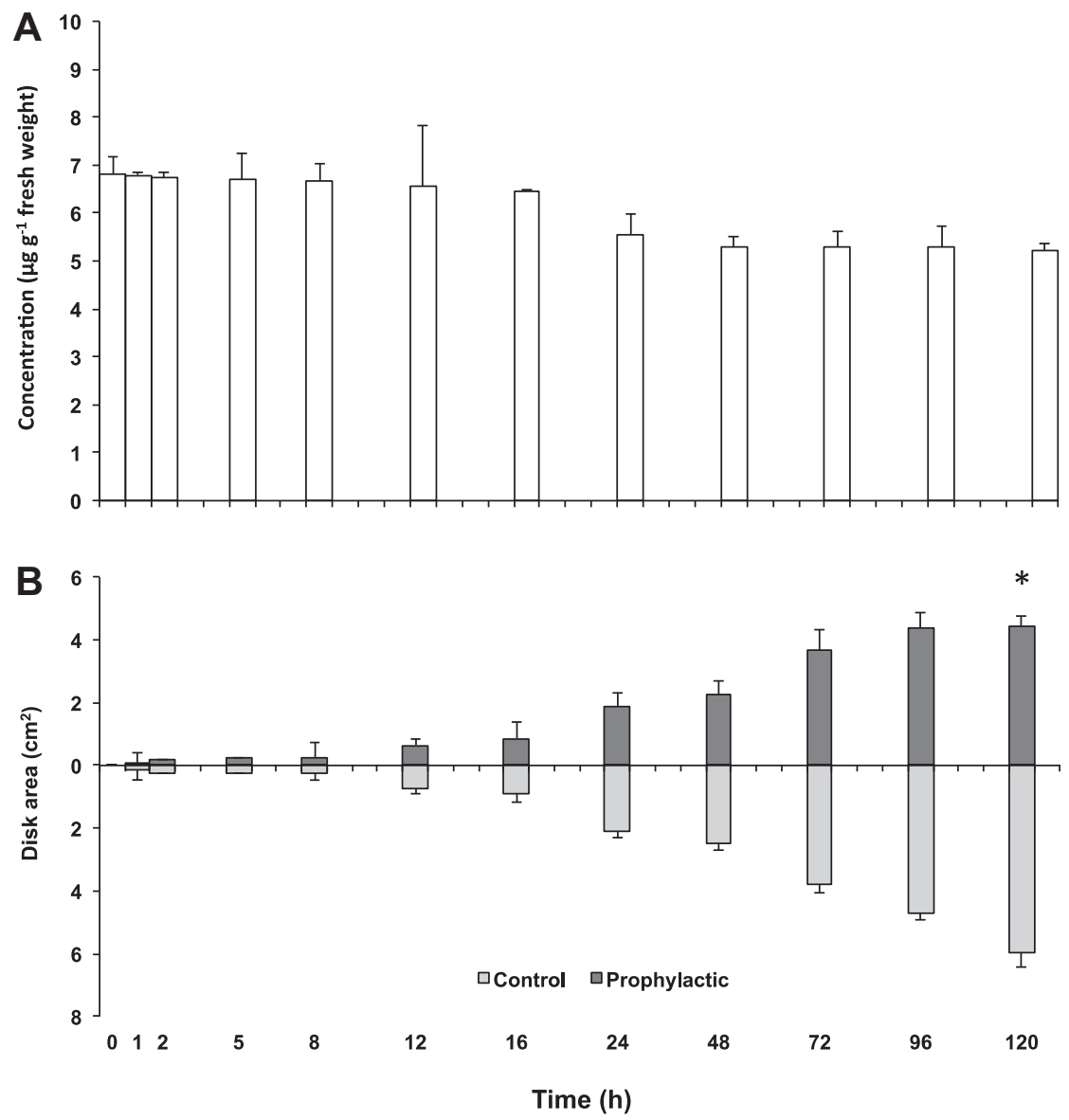

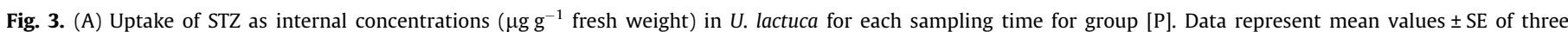

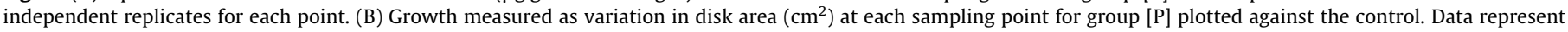
mean values \pm SE of three independent replicates for each point. Asterisk $\left(^{*}\right)$ indicates results significantly different from the control. 

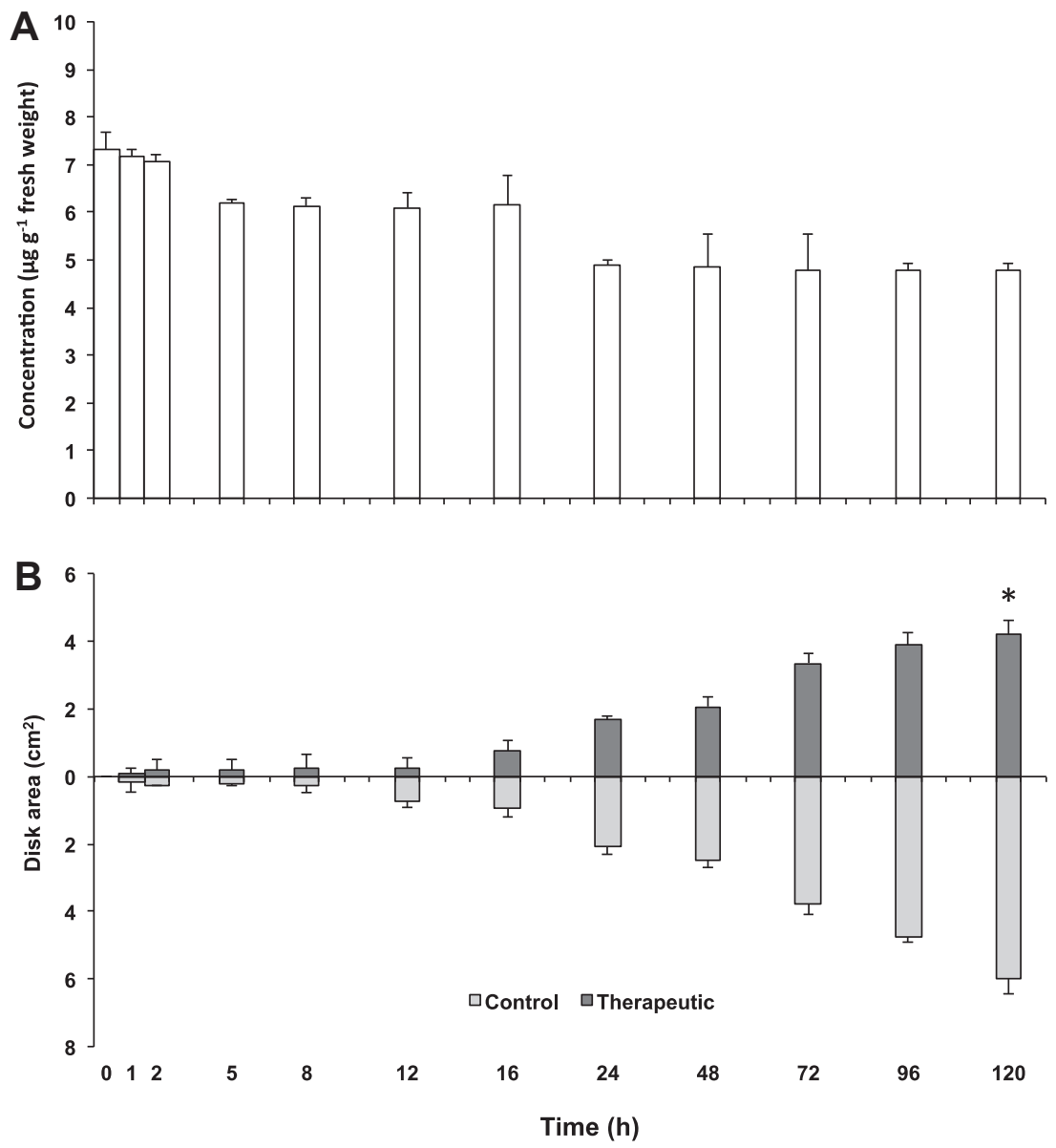

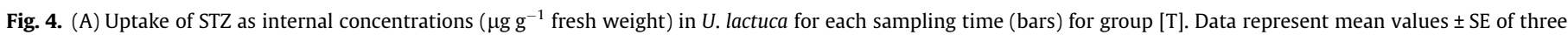

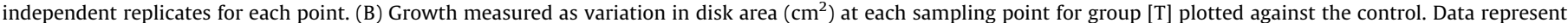
mean values \pm SE of three independent replicates for each point. Asterisk $\left(^{*}\right)$ indicates results significantly different from the control.

0.2 , which is higher than STZ and for this reason high internal concentrations were also expected in the present study. One likely explanation for the low concentrations found may reside in the protective detoxification mechanisms present in $U$. lactuca that are activated in the presence of xenobiotics to reduce the potential harmful effects (Sandermann, 1992; Coleman et al., 1997; Pflugmacher et al., 1999; Torres et al., 2008). Glutathione-S-transferases represent an important enzymatic complex in these systems with an active role in the degradation of STZ. It is possible that glutathione-S-transferases could have been involved in maintaining constant internal concentrations of the antibiotic while contributing to its reduction in the water (Park and Choung, 2007).

One important objective for the present work was to assess the possibility to use $U$. lactuca as a bioindicator and/or biomonitor species for the presence of STZ in the environment. Since the internal concentrations resulting from uptake were constant and unable to reflect the concentrations in the water the role of $U$. lactuca as a biomonitor is not in agreement with the necessary requirements. However, it can be used successfully as an indicator for the presence of STZ. Moreover, since U. lactuca can accumulate this contaminant and represents very high biomasses in natural ecosystems the risk of biomagnification along the trophic web is a serious concern.

\subsection{Growth}

One other crucial goal for the current research was to assess the influence of STZ on $U$. lactuca growth determined as variations in disk area. The results obtained with groups $\mathrm{P}$ and $\mathrm{T}$ were compared with control $\mathrm{B}$, which set the pattern of growth in the absence of antibiotic (Figs. 3B and 4B). Both dosages tested followed the increasing pattern of the control group but became statistically different after $120 \mathrm{~h}(p<0.05)$. At this time growth variations for $\mathrm{P}$ and $\mathrm{T}$ were lower than the control, respectively $4.43 \pm 0.34 \mathrm{~cm}^{2}$ (Group P) and $4.20 \pm 0.40 \mathrm{~cm}^{2}$ (Group T) against $5.26 \pm 0.47 \mathrm{~cm}^{2}$ (control B), indicating STZ had an inhibitory effect on macroalgal growth although not pronounced since severe effects such as chlorosis were not observed. The influence of STZ on macroalgal growth demonstrated in this work is in agreement with findings on the exposure of Lemna gibba to SA drugs (Brain et al., 2004) where growth inhibition was detected after $96 \mathrm{~h}$ for all the compounds tested. Pro et al. (2003) tested the influence of sulfachlorpyridazine on Lemna minor at several concentrations and the same trend of inhibition after $120 \mathrm{~h}$ was registered for all levels above $3 \mu \mathrm{g} \mathrm{mL}^{-1}$. Another study by Baran et al. (2006) reported that, along with other substances tested, STZ caused inhibition to the green algae Chlorella vulgaris.

The research on the potential effects of STZ to non-target aquatic organisms is a key factor in determining its role as an environmental contaminant. The phytotoxicity demonstrated in macroalgae is not surprising since photosynthetic organisms have similar folate pathways as bacteria. Folate, also known as Vitamin B9, is involved in the transfer of carbon units (C1) in metabolic pathways crucial to cellular division and growth, including the synthesis of nucleic acids and aminoacids, pantothenate (Vitamin B5, necessary for coenzyme-A formation) and chlorophyll. In pri- 
mary producers, it also has an important role in photorespiration. SA drugs are structural analogues of $p$-aminobenzoate (folate precursor) and through competition for the enzyme dihydropteroate synthase inhibit the formation of dihydropteroate, which is ultimately transformed to tetrahydrofolate (Hanson and Gregory, 2002; Basset et al., 2005; Brain et al., 2008). The resulting deficiency in folates will have severe consequences on cell division that in turn will be translated in diminished growth. Nonetheless, studies have demonstrated that STZ-induced inhibition is concentration and time dependent (Brain et al., 2004; Baran et al., 2006; Park and Choi, 2008). The dosages tested in the present work are very high and only likely to be found in natural ecosystems in areas at and very close to discharge points from aquaculture systems and therefore it is not expected that the tested prophylactic and therapeutic concentrations of STZ will have a severe impact on macroalgal growth in the concentrations usually reported for environmental waters, which are in the $\mathrm{ng} \mathrm{L}^{-1}$ to $\mu g \mathrm{~L}^{-1}$ range.

\section{Conclusions}

The environmental presence of a given substance and its potential to cause adverse effects in non-target organisms will depend greatly on its ability to resist degradation. In the present study it was found that STZ presents high stability in seawater at the concentrations tested thus representing a source of chemical pollution in natural waters. Nonetheless, the presence of $U$. lactuca greatly influenced the concentrations of STZ in solution by efficiently taking up the compound from the water while maintaining the internal values constant at both dosages tested, most likely through a detoxification mechanism. In environmental risk assessment this ability makes it a suitable choice as a bioindicator species but ecologically it represents the bioaccumulation potential of STZ which given the role of macroalgae as primary producers in trophic webs poses the risk of biomagnification.

\section{Acknowledgements}

This work was funded by FEDER through the Operational Program for Competitiveness Factors - COMPETE and by FCT - Portuguese Foundation for Science and Technology under the Grant attributed to Sara Leston (SFRH/BPD/91828/2012) and through the Project PTDC/AGR-ALI/122119/2010.

\section{References}

Akcali, I., Kucuksezgin, F., 2011. A biomonitoring study: heavy metals in macroalgae from eastern Aegean coastal areas. Mar. Pollut. Bull. 62, 637-645.

Andreozzi, R., Raffaele, M., Nicklas, P., 2003. Pharmaceuticals in STP effluents and their solar photodegradation in aquatic environment. Chemosphere 50, 13191330.

Baran, W., Sochacka, J., Wardas, W., 2006. Toxicity and biodegradability of sulfonamides and products of their photocatalytic degradation in aqueous solutions. Chemosphere 65, 1295-1299.

Basset, G.J.C., Quinlivan, E.P., Gregory, J.F., Hanson, A.D., 2005. Folate synthesis and metabolism in plants and prospects for biofortification. Crop Sci. 45, 449-453.

Bold, H.C., Wynne, M.J., 1978. Introduction to the algae-structure and reproduction. Prentice-Hall Inc., Englewood Cliffs, NJ.

Boreen, A.L., Arnold, W.A., McNeill, K., 2004. Photochemical fate of sulfa drugs in the aquatic environment: sulfa drugs containing five-membered heterocyclic groups. Environ. Sci. Technol. 38, 3933-3940.

Brain, R.A., Johnson, D.J., Richards, S.M., Sanderson, H., Sibley, P.K., Solomon, K.R. 2004. Effects of 25 pharmaceutical compounds to Lemna gibba using a sevenday renewal test. Environ. Toxicol. Chem. 23, 371-382.

Brain, R.A., Ramirez, A.J., Fulton, B.A., Chambliss, C.K., Brooks, B.W., 2008. Herbicidal effects of sulfamethoxazole in Lemna gibba: using p-aminobenzoic acid as a biomarker of effect. Environ. Sci. Technol. 42, 8965-8970.

Braschi, I., Blasioli, S., Gigli, L., Gessa, C.E., Alberti, A., Martucci, A., 2010. Removal of sulfonamide antibiotics from water: evidence of adsorption into an organophilic zeolite Y by its structural modifications. J. Hazard. Mater. 178, 218-225.
Coleman, J.O.D., Blake-Kalff, M.M.A., Emyr Davies, T.G., 1997. Detoxification of xenobiotics by plants: chemical modification and vacuolar compartmentation. Trends Plant Sci. 4, 144-151.

Coogan, M.A., Edziyie, R.E., La Point, T.W., Venables, B.J., 2007. Algal bioaccumulation of triclocarban, triclosan, and methyl-triclosan in a North Texas wastewater treatment plant receiving stream. Chemosphere 67, 1911 1918.

Costa, S., Crespo, D., Henriques, B.M.G., Pereira, E., Duarte, A.C., Pardal, M.A., 2011. Kinetics of mercury accumulation and its effects on ulva lactuca growth rate at two salinities and exposure conditions. Water Air Soil Poll. 217, 689-699.

Fatta-Kassinos, D., Meric, S., Nikolaou, A., 2011. Pharmaceutical residues in environmental waters and wastewater: current state of knowledge and future research. Anal. Bioanal. Chem. 399, 251-275.

García-Galán, M.J., Díaz-Cruz, M.S., Barceló, D., 2008. Identification and determination of metabolites and degradation products of sulfonamide antibiotics. Trac - Trend Anal. Chem. 27, 1008-1022.

Halling-Sorensen, B., Nielsen, S.N., Lanzky, P.F., Ingerslev, F., Holten Lutzhoft, H.C. Jorgensen, S.E., 1998. Occurrence, fate and effects of pharmaceutical substances in the environment-a review. Chemosphere 36, 357-393.

Hanson, A.D., Gregory, J.F., 2002. Synthesis and turnover of folates in plants. Curr. Opin. Plant Biol. 5, 244-249.

Hruska, K., Franek, M., 2012. Sulfonamides in the environment: a review and a case report. Vet. Med-Czech 57, 1-35.

Ji, K., Kim, S., Han, S., Seo, J., Lee, S., Park, Y., Choi, K., Kho, Y.-L., Kim, P.-G., Park, J. Choi, K., 2012. Risk assessment of chlortetracycline, oxytetracycline, sulfamethazine, sulfathiazole, and erythromycin in aquatic environment: are the current environmental concentrations safe? Ecotoxicology 21, 2031-2050.

Kahle, M., Stamm, C., 2007. Time and pH-dependent sorption of the veterinary antimicrobial sulfathiazole to clay minerals and ferrihydrite. Chemosphere 68 , 1224-1231.

Kim, J., Park, Y., Choi, K., 2009. Phototoxicity and oxidative stress responses in Daphnia magna under exposure to sulfathiazole and environmental leve ultraviolet B irradiation. Aquatic Toxicol. 91, 87-94.

Kümmerer, K., 2001. Drugs in the environment: emission of drugs, diagnostic aids and disinfectants into wastewater by hospitals in relation to other sources-a review. Chemosphere 45, 957-969.

Kümmerer, K., 2009. Antibiotics in the aquatic environment - a review - Part I. Chemosphere 75, 417-434.

Lertpaitoonpan, W., Ong, S.K., Moorman, T.B., 2009. Effect of organic carbon and pH on soil sorption of sulfamethazine. Chemosphere 76, 558-564.

Leston, S., Nunes, M., Viegas, I., Lemos, M.F.L., Freitas, A., Barbosa, J., Ramos, F., Pardal, M.A., 2011. The effects of the nitrofuran furaltadone on Ulva lactuca. Chemosphere 82, 1010-1016.

Leston, S., Nunes, M., Viegas, I., Ramos, F., Pardal, M.A., 2013. The effects of chloramphenicol on Ulva lactuca. Chemosphere 91, 552-557.

Lunestad, B.T., Samuelsen, O.B., Fjelde, S., Ervik, A., 1995. Photostability of eight antibacterial agents in seawater. Aquaculture 134, 217-225.

Melville, F., Pulkownik, A., 2007. Investigation of mangrove macroalgae as biomonitors of estuarine metal contamination. Sci. Total Environ. 387, 301-309.

Michelini, L., Meggio, F., La Rocca, N., Ferro, S., Ghisi, R., 2012. Accumulation and effects of sulfadimethoxine in Salix fragilis L. plants: a preliminary study to phytoremediation purposes. Int. J. Phytoremediation 14, 388-402.

Park, S., Choi, K., 2008. Hazard assessment of commonly used agricultural antibiotics on aquatic ecosystems. Ecotoxicology 17, 526-538.

Park, H., Choung, Y.-K., 2007. Degradation of antibiotics (Tetracycline, Sulfathiazole, Ampicillin) using enzymes of glutathion S-transferase. Hum. Ecol. Risk Assess. 13, 1147-1155.

Pérez, S., Eichhorn, P., Aga, D.S., 2005. Evaluating the biodegradability of sulfamethoxazole, sulfathiazole and trimethoprim at different stages of sewage treatment. Environ. Toxicol. Chem. 24, 1361-1367.

Pflugmacher, S., Wiencke, C., Sandermann, H., 1999. Activity of phase I and phase Il detoxification enzymes in Antarctic and Arctic macroalgae. Mar. Environ. Res. 48, 23-36.

Pro, J., Ortiz, J.A., Boleas, S., Fernández, C., Carbonell, G., Tarazona, J.V., 2003. Effect assessment of antimicrobial pharmaceuticals on the aquatic plant Lemna minor. Bull. Environ. Contam. Toxicol. 70, 290-295.

Rainbow, P.S., Phillips, D.J.H., 1993. Cosmopolitan biomonitors of trace metals. Mar Pollut. Bull. 26, 593-601.

Sandermann, H., 1992. Plant metabolism of xenobiotics. Trends Biochem. Sci. 17 $82-84$.

Sarmah, A.K., Meyer, M.T., Boxall, A.B.A., 2006. A global perspective on the use, sales, exposure pathways, occurrence, fate and effects of veterinary antibiotics (VAs) in the environment. Chemosphere 65, 725-759.

Swindol, M., Stahl, R.G., Ells, S.J., 2000. Natural remediation of environmental contaminants: its role in ecological risk assessment and risk management. Soc. Environ. Toxicol. Chem. (SETAC).

Torres, M.A., Barros, M.P., Campos, S.C.G., Pinto, E., Rajamani, S., Sayre, R.T. Colepicolo, P., 2008. Biochemical biomarkers in algae and marine pollution: review. Ecotoxicol. Environ. Safe. 71, 1-15.

Villares, R., Puente, X., Carballeira, A., 2002. Seasonal variation and background levels of heavy metals in two green seaweeds. Environ. Pollut. 119, 79-90.

Walker, C.H., Hopkin, S.P., Sibly, R.M., Peakall, D.B., 2006. Principles of Ecotoxicology, third ed. CRC Press Taylor and Francis Group, Boca Raton. 